\title{
A FORMA SEVERA - AJUSTES DE ROTEIRO EM MURILO MENDES
}

\section{Júlio Castañon Guimarães}

A afirmação de Valéry de que “o que é a 'forma' para qualquer outro, é o 'fundo' para mim” (VALÉRY, 1980a, 1456), afirmação que em termos gerais parecerá problemática, poderá, porém, ser mais bem lida no contexto não só de sua própria produção poética, mas também, e talvez sobretudo, no de sua própria produção crítica. Encontra uma versão de certo modo explicativa, numa chave pragmática, na seguinte passagem: "Quanto a mim, que, confesso, sou muito mais atento à formação ou à feitura das obras que às próprias obras, tenho o hábito ou a mania de só apreciar as obras como ações" (VALÉRY, 198ob, 1329). Os encaminhamentos da produção de Murilo Mendes, em associação com alguns episódios de sua correspondência adiante abordados, podem ser encarados na perspectiva de algumas questões formais ou, para circunscrever um pouco o âmbito da discussão, no plano mais prático de alguns problemas técnicos - no sentido dessas ações de que fala Valéry ou mesmo, para guardar certa prudência, no sentido de intenções de ações ${ }^{1}$.

1 O título deste artigo tem origem na reiteração das palavras "forma" e "severa" no livro Siciliana, em especial no poema "As ruínas de Selinunte": "[...] formas elaboradas no futuro, / Severas tombando". 
Após Poesia liberdade, há reconhecidamente um novo encaminhamento na produção poética de Murilo. Há modificações de natureza formal, assim como o surgimento de novos temas ou pelo menos de novos pontos de vista. Contemplação de Ouro Preto permite perceber isso. Os poemas longos, a metrificação, as formas regulares, a temática geográfica e cultural, o tom reflexivo - tudo o que está em Contemplação de Ouro de Preto aparece também, com variações maiores ou menores em livros como Sonetos brancos e Parábola. Os livros que vêm a seguir, Siciliana e Tempo espanhol, introduzem alguns aspectos novos aos quais se pode referir por meio da noção de "substantivação", exposta no conhecido artigo de Haroldo de Campos (CAMPOS, 1967). Em relação a esses dois livros parece-me que cabe referir uma circunstância biográfica que tem a ver com o tema deste encontro². Pelas datas de elaboração, são livros anteriores à instalação de Murilo na Itália; já são livros, porém, não apenas de temática europeia, mas elaborados num período em que o autor como que experimenta a Europa. A transferência para a Itália se dá uns cinco anos depois da época em que, com idas e vindas entre Brasil e Europa, ocorrem períodos mais prolongados na Bélgica, algumas idas à França e uma tentativa frustrada de ficar na Espanha. A instalação na Itália dá-se, assim, após uma certa experiência europeia, situando-se nesse contexto mais amplo e constituindo a possibilidade de prolongamento dessa experiência europeia (viagens, contatos, museus, escrita de textos sobre lugares e pessoas, e assim por diante).

Lembrando a referência inicial sobre a modificação formal, veja-se a seguinte observação feita por Murilo numa carta dirigida a Haroldo de Campos. É uma carta de 1963, em que ele manifesta

satisfação pelo fato de um poeta do seu valor e da sua cultura reconhecer no autor de Tempo espanhol domínio estilístico, quando quase toda a crítica negava ou duvidava do fato (com única exceção talvez do Eduardo Portella, que o reconheceu ao escrever sobre as Poesias 1925-1955). A maioria apoiava-se no famoso artigo de Mário de Andrade sobre A poesia em pânico, esquecendo-se (ou fingindo ignorar) que em passagens posteriores o mesmo Mário escreveu coisas muito diversas a meu respeito³.

2 Trata-se do seminário Ipotesi/Hipóteses: Murilo Mendes e a Itália, realizado no Museu de Arte Murilo Mendes, da UFJF, 17 e 18 de outubro de 2011.

3 As cartas dirigidas a Haroldo de Campos aqui citadas foram publicadas no catálogo da exposição Murilo Mendes 1901-2001 (Centro de Estudos Murilo Mendes, UFJF, 2001). As cartas dirigidas a João Cabral de Melo Neto encontram-se depositadas no Arquivo-Museu de Literatura Brasileira da Fundação Casa de Rui Barbosa, onde foram consultadas. 
Tantos anos depois, o artigo de Mário de Andrade (saído na imprensa em 1939, com o título do livro de Murilo, e depois recolhido no volume $O$ empalhador de passarinho) com suas restrições à elaboração dos poemas, continua a incomodar um Murilo que a esta altura atribui cada vez mais importância a esse aspecto de sua atividade, o aspecto que, de modo sumário, se poderia dizer "técnico". Nessa carta há ainda uma outra observação que tem interesse para a compreensão desse período de Murilo: "seus artigos [de Haroldo de Campos sobre Tempo espanhol] constituem o reconhecimento de um trabalho sério, aprofundado, não baseado apenas em impulsos líricos. Sou-lhe muito grato, e eu, que há 5 anos não escrevo versos, estou tentado a recomeçar". Um dos pontos de mais interesse aqui é a menção ao fato de não estar escrevendo versos, o que não significa "não escrever", como se verá. Cerca de quatro anos depois, em outra carta também a Haroldo de Campos, Murilo refere o recebimento do número cinco da revista Invenção (dez. 1966-jan. 1967) e agradece a "boa colocação dos meus textos". A revista publicou poemas de Murilo, poemas integrantes do livro Convergência que estava à espera de publicação na editora Duas Cidades, como é mencionado na mesma carta, e que viria a ser publicado por essa editora em 1970. E aí se tem ainda um outro movimento de modificação (assinalado pela publicação na revista concretista), constituído pelo conjunto de poemas de Convergência, com suas experiências formais.

Quando refere não estar escrevendo poesia, Murilo estava na verdade escrevendo intensamente prosa. E nesse período por mais de uma vez menciona seu crescente interesse pela prosa, tendo então produzido muito, um grande número de textos em prosa que se reuniram em vários livros, em sua maioria só publicados postumamente - Idade do serrote, Poliedro, Carta geográfica, Espaço espanhol, Retratos-relâmpago, A invenção do finito, Janelas verdes, Conversa portátil. Tem-se então, no período italiano, ao lado das modificações formais, essa intensa prática da prosa. A pergunta que talvez se possa fazer é se é possível extrair dessas aproximações algo que contribua para uma melhor compreensão do andamento da obra de Murilo.

Ainda é preciso, porém, acrescentar a esses elementos dois outros dados. O primeiro é a intensa frequência com que Murilo escreveu sobre artes plásticas - coisa que ele já fazia anteriormente, mas de modo diferente, pois menos frequentemente e com um texto de outra natureza. O segundo é a prática de outras línguas que não o português - além do italiano, escreveu também em francês -, e essa prática não era circunstancial. 
Uma primeira ligação entre alguns desses dados se dá justamente pelo fato de boa parte da prosa desse período ser a prosa sobre artes plásticas. Pode-se falar em crítica de arte, mas nem sempre a expressão parece inteiramente adequada, pois muitos dos textos não têm as características habituais de um texto de crítica de arte e se aproximam de textos de outra natureza, como até mesmo o poema, com os quais de fato muitas vezes se confundem. É conhecido o texto em que Giulio Carlo Argan fala justamente sobre a natureza desses textos de Murilo: "Para Murilo Mendes a crítica de arte era um gênero literário, era um capítulo do seu trabalho poético. Às vezes o texto crítico conserva a métrica da poesia, com mais frequência nasce como fato poético, depois, em uma segunda versão, configura-se como prosa e se serve com discreta e espontânea propriedade da terminologia técnica da crítica de arte" (ARGAN, 1984, 13).

A justeza da observação de Argan é ainda mais digna de atenção quando se considera que ela terá sido feita a partir do contato com os textos que iam aparecendo aqui e ali, em diferentes publicações. Não havia uma reunião desses textos. Hoje as várias reuniões já publicadas permitem verificar não só a pertinência dessa observação, mas mesmo examiná-la de modo detalhado a partir de diversas informações que vão se tornando disponíveis. Ao lado do fato de que Murilo se interessava justamente por poetas que escreviam em prosa, como é o caso de Francis Ponge (lembre-se a referência feita em poema de Convergência), e de que leu um livro como o de Suzanne Bernard sobre o poema em prosa (o exemplar que lhe pertenceu traz marcas de leitura e anotações), tem-se também algum conhecimento sobre a organização de seus próprios livros de prosa (nas notas da edição de Poesia completa e prosa, de 1994), de modo que se pode pelo menos ter uma ideia de que essa organização não era um simples agrupamento de textos produzidos circunstancialmente. Com certeza não se poderá imaginar que todos os textos tenham sido produzidos no contexto de um projeto antecipadamente definido, mas se poderá supor que o tenham sido no contexto de uma preocupação, de uma reflexão sobre a questão, e no contexto de algumas outras questões relacionadas. Entre elas está a da situação linguística desses textos, ou seja, o fato de serem inicialmente publicados em tradução (feita por diferentes tradutores do português para o italiano) ou de serem produzidos em italiano ou francês e a seguir traduzidos para o português pelo próprio autor. Assim, não se pode deixar de levar em conta o fato de que especificamente vários dos textos de crítica de artes produzidos na Itália transitam entre o italiano e o português - escritos às vezes em italiano, foram revistos por terceiros e a seguir traduzidos pelo 
próprio autor para o português. As notas ao volume L'occhio del poeta, por exemplo, fornecem vários dados sobre esses casos. Semelhante é o que acontece com alguns textos em francês - Murilo informa (em algumas cartas, por exemplo ${ }^{4}$ ) tê-los escrito diretamente em francês, ter solicitado a alguém que os lesse e corrigisse, referindo ainda que seu texto em francês foi considerado muito bom e que se sente relativamente à vontade escrevendo em francês.

Em relação ao trabalho com a prosa de modo geral, há algumas declarações de Murilo em sua correspondência, sobretudo com João Cabral de Melo Neto, que merecem referência, pois são muito esclarecedoras do que se pode de fato considerar como uma proposta de trabalho. Numa carta de 1962, ele diz:

Pessoalmente não acho saída para a crise da linguagem da minha poesia. Há 4 anos não escrevo versos, por impossibilidade de projetar coisas novas. Mallarmé: "le silence, seul luxe après les rimes". No momento escrevo só em prosa, que me induz a restringir a fantasia, economizar a metáfora, disciplinando-me mais. Leio muito ensaio - filosofia, estética, artes plásticas, histórica, e pouco poesia.

Aqui, ainda que brevemente, Murilo aprofunda sua afirmação de que está sem escrever poesia, justificando o fato por uma "crise da linguagem”. Assim, esta faz com que ele não escreva poesia, mas talvez não se possa deduzir que seja essa mesma crise que o faça escrever prosa. Supondo, porém, que seja, é no âmbito dessa crise que ele identifica ao mesmo tempo certos procedimentos que desenvolve na prática da prosa, uma técnica ou uma disciplina (que de resto se aplicam à sua poesia que precede de pouco esse período ou a que se produzirá logo a seguir, como se pode ver em Convergência e em Ipotesi). Aqui se pode pensar de modo mais claro que a prosa de aparência circunstancial do período (textos eventuais para catálogos) não escapava a uma intenção mais incisiva e que constituía um espaço de experimentação. Nessa experimentação, o objeto dos textos, as obras plásticas, constituía sem dúvida um elemento de interlocução, que podia contribuir para o desenvolvimento de suas reflexões. Escreveu sobre artistas muito diferentes, mas em vários momentos é possível perceber que o caráter circunstancial da produção do texto não impede que este de algum modo se desenvolva em função do diálogo com seu objeto, desencadeador assim das experiências que são

4 Em cartas à sua irmã Virgínia, depositadas no Museu de Arte Murilo Mendes, da UFJF. 
as várias formas que os textos assumem. Essa situação naturalmente tem a ver com o fato de Murilo estar na Itália, mas não o limita a um diálogo italiano, por assim dizer, permitindo uma dimensão mais ampla, pois se pode lembrar que nesse período escreveu também sobre alguns artistas não italianos, como Arp, Brauner, Sonia Delaunay, Duchamp, Max Ernst, Hans Richter, Henrique Ruivo, além dos brasileiros De Lamonica, Ianelli, Volpi, Weissmann.

No mesmo ano de 1962, numa carta também a João Cabral de Melo Neto, Murilo fala de um texto sobre o artista italiano Turcato. Anuncia ele:

Com o texto sobre Turcato pretendo iniciar uma série de pequenos "retratos" de pintores. Chateado com a maioria dos críticos de arte, que, ou caem num bizantinismo e pedantismo incríveis, ou então num prosaísmo jornalístico, procuro (para mim, é claro, não para outrem) uma via diversa - entre a crítica, a informação e a poesia. [...] Escrevi diretamente em francês, mas farei também um texto em português.

Aqui Murilo dá uma nova formulação para seu projeto de escrita de prosa - na carta anteriormente mencionada, referia o que se pode considerar como procedimentos de escrita, enquanto aqui refere algo mais abrangente, o estatuto do texto no plano dos gêneros. As leituras a que se dedica dizem bastante do espaço amplo, não compartimentado ou não excludente em que se move. Evidentemente não se trata de uma situação em que tudo esteja concatenado de forma rigorosa. Aqui se está de modo claro no terreno da exploração, da experimentação. Se antes ele falava na impossibilidade de escrever poesia, o que o levava para a prosa, agora a prosa se associa à poesia. Não à toa, alguns objetos de seus textos em prosa, ou seja, alguns artistas plásticos, serão também tema de poemas. O trecho da carta deixa claro também que a associação de que aqui se fala faz parte da experimentação que ainda se estende à exploração de uma outra língua. E a palavra com que Murilo resume esse seu novo encaminhamento - esse projeto, ou melhor seria dizer esboço de projeto - é "retrato", o que não é um mero acaso, pois ela virá a ser título de um de seus livros produzidos nesse período, o Retratos-relâmpago, que não inclui apenas artistas plásticos - é como se essa ideia inicial exposta na carta viesse a ganhar com o tempo um alcance mais amplo.

Tudo isso envolve um conjunto de concepções e procedimentos que se poderia considerar de natureza técnica, para usar, com alguma reticência, uma palavra que pode não ser inteiramente precisa mas que talvez dê conta de sinalizar o que está em jogo. Todavia, já algum tempo antes, em 1959, em outra carta ao mesmo João Cabral de Melo Neto, Murilo 
diz estar continuando o "trabalho de polimento" de Tempo espanhol e que se tornou um "torturado da forma". Ora, quando é publicado o livro de poemas Convergência, em 1970, com poemas então desse período de que estamos nos ocupando, chamou especialmente a atenção da crítica o aspecto de experimentação de boa parte dos poemas, experimentação no sentido linguístico, como invenção vocabular ou jogos de palavra. Há no livro, porém, um outro aspecto que se associa a essa invenção e que por isso mesmo, apesar de ser um recurso a elementos tradicionais, participa também da atitude renovadora que marca o livro. Trata-se do uso da metrificação. Esta, no caso, pode ser considerada, numa certa perspectiva, como uma metrificação com desenvoltura, o que suporia uma dose de liberdade graças ao manejo destro, à vontade, dos elementos do verso; ou, numa outra perspectiva, poderia ser considerada apenas como uma metrificação às vezes aproximativa, talvez até pelo manejo destro não ser o objetivo no caso - o objetivo na verdade seria a inserção da metrificação no conjunto dos diversos procedimentos inventivos do livro. Só a título de lembrete, podem ser citados poemas como "Murilograma a João Sebastião Bach", "Murilo a Debussy", "Murilograma a Camões”, "Murilograma a João Cabral de Melo Neto". Só estes exemplos já permitiriam levantar algumas possibilidades de situar a metrificação em um diálogo seja com a temática musical, seja com a tradição, seja com o uso peculiar que dela fazia um poeta como João Cabral de Melo Neto.

É ainda na correspondência com João Cabral que se encontram algumas outras informações bastante importantes e que merecem ser levadas em conta para o conhecimento desse período da obra de Murilo. Numa carta de 1957, enviada de Roma, Murilo anuncia como que sua dedicação intensiva à poesia italiana:

Infelizmente os dois poetas mais interessantes da Itália atual residem em Milão - Montale e Quasímodo. Os italianos, mesmo cultos, escritores etc., consideram Montale dificílimo, super-hermético etc. Entretanto tenho lido os poemas dele com relativa facilidade. O vocabulário é rico e precioso, a construção muito pessoal. Estou lendo palavra por palavra; quanto aos bizantinismos de construção, a intuição de poeta muito me ajuda. Quasimodo tem traduções maravilhosas dos poetas gregos e latinos, mormente Homero, Sófocles e Catulo. Já li quase tudo. Tenho lido também os poetas do dolce stil nuovo, mormente Guido Cavalcanti. De Dante, um ou outro canto dos mais fáceis. E me aventuro também no Petrarca (roubadíssimo pelo nosso preclaro Camões) que é bem difícil.

Ao lado de seu esforço para conhecer a literatura italiana que lhe era contemporânea, parece especialmente importante o empenho de 
conhecimento dos clássicos e a ligação entre esse conhecimento e o da língua italiana. Talvez os dois últimos dados é que tenham mais estreita relação com as concepções de Murilo nesse período. Assim, numa carta de dois anos depois, 1959, sempre a João Cabral, diz Murilo numa enfatização do que já informava na carta acima citada: "Estou metido até a medula em Dante e Petrarca, estudando-os palavra por palavra”.

No ano seguinte, 1960, em outra carta a João Cabral, diz Murilo: "Mando-lhe também duas canções de Dante em torno do tema mulherpedra - com ligeiras notas. Dado o seu conhecimento do português, francês e espanhol, penso que as entenderá. Caso não, mande me dizer: ajudado pela tradutora Saudade tentarei uma versão aproximada"s. Anexada à carta está uma cópia das duas canções e ainda uma página com comentários de Murilo sobre detalhes de vária natureza do texto. A escolha desses textos enviados a João Cabral, textos especialmente difíceis, e os comentários atestam o envolvimento de Murilo com as questões muito específicas. Vale lembrar que por essa época Haroldo de Campos e Augusto de Campos estavam traduzindo os textos publicados no volume de 1968 Traduzir E trovar (poetas dos séculos XII a XVII) e que Haroldo se correspondia com Murilo, conforme já visto por cartas acima referidas. Entre as traduções do volume Traduzir \& trovar estão justamente as "Rimas pedrosas" ("Rime petrose"), traduzidas por Haroldo, entre as quais se incluem os dois poemas referidos por Murilo ("Al poco giorno e al gran cerchio d'ombra" [Ao dia escasso e ao grande anel de sombra] e "Amor, tu vedi ben che questa donna" [Amor, repara bem que esta senhora]). Murilo esteve de fato envolvido com essas traduções, pois em carta dirigida a Ruggero Jacobbi enviou a este comentários a essas traduções, que fizera a pedido de Haroldo, e lhe pedia que também fizesse comentários, que eram esperados por Haroldo ${ }^{6}$.

5 A propósito dessa proposta de tradução informal, por assim dizer, pode-se lembrar de que Murilo praticamente não fez trabalhos de tradução, até onde se tem conhecimento. Além de alguns de seus próprios textos do período italiano que ele teria escrito em italiano e francês a seguir passado para o português, traduziu dois poemas do chileno Arturo Torres Rioseco, "Rosa fria" e "Silêncio", incluídos no volume Poesias (Porto Alegre: Globo, 1945 - coletânea de poemas de Torres Rioseco traduzidos por nomes como Carlos Drummond de Andrade, Manuel Bandeira, Oswald de Andrade, entre outros. Traduziu ainda do francês o livro A filosofia social e política do confucionismo, do frade franciscano João Batista Se-Tsien Kao O.F.M. (Rio de Janeiro: s.e., 1952).

6 Devo a Maria Betânia Amoroso a informação sobre a existência dessa carta (por ela consultada no arquivo particular de Mara Jacobbi, viúva de Ruggero Jacobbi) e sobre seu conteúdo. 
Para ressaltar um pouco o persistente esforço de estudo por parte de Murilo, veja-se ainda este trecho de carta que escreveu a João Cabral, já em 1962:

\begin{abstract}
Li todo o Guido Cavalcanti, minuciosamente. Agora estou lendo outros poetas italianos do século XIII. A meu ver muito mais perto de nós do que os do século XVI - para não falar nos barrocos e nos românticos; Pound tem razão. Tenho tido muito trabalho com essa leitura, difícil mesmo para italiano culto, mas vale a pena. Dispomos de uma edição anotadíssima - pelo especialista Contini - (dois grossos volumes, presente de Natal de Saudade). Se não fosse isto, a decifração dos textos seria um inferno.
\end{abstract}

Algumas questões podem ser levantadas a partir desses dados (que naturalmente precisam ser muito ampliados), como de início a relação dessas leituras com sua própria produção. Referindo-se a autores como Ezra Pound, Georges Steiner fala do "movimento modernista como uma estratégia de permanente exílio. $\mathrm{O}$ artista e o escritor são turistas incessantes olhando as vitrines de todo o âmbito das formas disponíveis". (STEINER, 1990, 27) Entendendo-se "exílio", nem no sentido estrito, nem no sentido amplo de uma metáfora aplicável a qualquer situação, mas como condição de deslocamento, compreende-se esse "turista" atento àquilo de que sua imaginação e seu conhecimento podem apropriar-se na elaboração de seu trabalho. Não é à toa que Steiner fala em "formas", pois, no caso da poesia, está em questão um deslocamento linguístico, cultural; estão em questão línguas e suas literaturas.

Não é o caso aqui de fazer um levantamento na obra de Murilo de menções mais ou menos claras àqueles autores que ele menciona em suas cartas como objeto de suas leituras e estudo. Um tanto ao acaso, é possível lembrar alguns casos mais evidentes, como os textos "Dante" e "Petrarca" de Retratos-relâmpago, em que também há textos sobre poetas como "Cecco Angioleri" e "Folgore da San Gimignano"; ou um poema como "Murilograma a Guido Cavalcanti" (de Convergência), que tem como epígrafe versos da Comédia de Dante. Além desses, há também um texto não incluído em livro, "Pia de' Tolomei", baseado num episódio da Comédia de Dante. Esses são os resultados mais visíveis do que é pelo menos em parte exposto nas cartas. No conjunto as leituras formariam uma "memória poética", para usar a expressão de Jacqueline Risset, que encara essa memória não simplesmente como um acúmulo de informações, como um arquivo, mas como uma "caixa de ressonância no sentido musical, que é ao mesmo tempo laboratório de uma elaboração frenética". (RISSET, 2007, 20) Além de casos como os dos exemplos referidos, uma hipótese que parece plausível é a de que 
o conhecimento literário adquirido por Murilo nesse período se integra à sua própria produção, à sua "oficina-laboratório" (denominação encontrada em seu "Murilograma a C.D.A.", Convergência) de modo mais propriamente técnico, como na associação entre experimentalismo e métrica presente em Convergência. Sempre será difícil especificar com precisão as atividades desse tipo de "oficina-laboratório", mas não há como não identificar nela o espaço daquelas ações de que fala Valéry e de que os elementos referidos, por exemplo, nas cartas aqui mencionadas são consideráveis componentes.

\section{REFERÊNCIAS BIBLIOGRÁFICAS}

ARGAN, Giulio Carlo. "L'occhio del poeta, ovvero i ventagli di Murilo Mendes". In Letteratura d'America. Anno V, n. 23, Estate, 1984.

CAMPOS, Haroldo de. "Murilo e o mundo substantivo". In Metalinguagem. Petrópolis: Vozes, 1967.

RISSET, Jacqueline. Traduction et mémoire poétique. Paris: Hermann, 2007.

STEINER, George. Extraterritorial. A literatura e a revolução da linguagem. São Paulo: Companhia das Letras, 1990.

VALÉRY, Paul. “Calepin d'un poète”. In Oeuvres, vol. I, Gallimard, 1980a. . "Poésie et pensée abstraite”. In Oeuvres, vol. I, Gallimard, 198ob. 
O texto de Murilo Mendes "Pia de' Tolomei”, em prosa, foi publicado, juntamente com "Fedra", também em prosa, numa revista editada pelo poeta português Alberto de Lacerda, que à época vivia em Boston, onde ensinava na universidade. O título da revista era Maio, e seu subtítulo "International Poetry Magazine". Vinha com as seguintes indicações: "Edited by Alberto de Lacerda. Number 1. Covers by Jorge Guillén. 1973". Da folha de rosto consta a seguinte lista de colaboradores: Jorge Guillén, Murilo Mendes, Octavio Paz, Anne Beresford, Mário Cesariny, Júlio Pomar, Dominique Fourcade, Celia Gilbert, Ben Norwood, Ruth Lepson, Claude Joyet-Journoud, Augusto de Campos, David Wevill, Luís Amorim de Sousa, David Steiling. Hoje raríssima, a revista teve apenas esse número, em que as letras da capa são de Jorge Guillén (cf. Colecção Alberto de Lacerda. Um olhar. Lisboa: Assírio \& Alvim, Fundação Mário Soares, 2009). O primeiro texto de Murilo tem a ver com o assunto deste artigo; já não tão diretamente o segundo. Todavia, a publicação aqui de ambos se justifica pelo fato de serem inéditos em livro. Em "Pia de' Tolomei", a indicação da passagem da Comédia de Dante constitui referência para a fonte que inspirou o texto. Em "Fedra", as duas passagens em francês são provenientes da Phèdre de Racine. (J.C.G.)

Pia de' Tolomei

\section{Purgatorio V, 130/136}

Subsiste para mim, perenemente aludindo à sua história iterativa. Não me importa que tenha sido abolida em fins do século XIII. Alguns séculos contarão diante dos milênios que nos precederam? Pia de' Tolomei usa a palavra, agora, enquanto na rua um cortejo político, nova procissão, levanta os braços vermelhos. Gira no espaço de si própria. A lua, conscientemente supérflua, revoga-se. Pia de' Tolomei suspende o tempo, categoria provisória. Num só verso descreve a dupla linha nascimento-morte: "Siena mi fé; disfecemi Maremma". Agora Siena e Maremma encontram-se no lugar absoluto do texto, fora das coordenadas euclidianas. Pia de' Tolomei, sim, foi, é, será: distante da espada-górgone de Messer Nello que a fez precipitar do balcão num vale de ossos; liberta da alienação, das fezes, do televisor e dos ritos de Proserpina, pede o sim de cada um de nós: "Ricorditi di me, che son la Pia". 


\section{0 - Remate de Males 32.1 \\ Fedra}

Fedra espaventa o manequim do sol seu antepassado, recusa o diadema da Rainha Triangular do Primeiro Egito, a solidariedade dos cavalos, a música e os navios que a distraem do seu furor, queima os papéis de Aristóteles. Respira ao mesmo tempo o incesto e a impostura. Cada palavra põe seus cabelos em pé; as janelas gritam. A carne é sua galáxia única, o labirinto seu ar. Desafia a guerra. Alimentada pelo terror interno, torna a paixão sua própria muralha. Tudo, excetuando a magia do relâmpago-Hipólito, resulta-lhe supérfluo, revogável. "Que ces vains ornements, que ces voiles me pèsent!" A bomba do veneno atinge-lhe as pupilas.

Nem de outro modo poderia agir La fille de Minos et de Pasiphaé.

Roma, 1973 
The editor wishes to express his deep gratitude for the generous help of Boston University, which made it possible to bring out the first number of this magazine.

All the poems are published here for the very

first time

Correspondence should be addressed to

Alberto de Lacerda 48A Primrose Mansions

Prince of Wales Drive

London, S.W. 11

England 
32 - Remate de Males 32.1

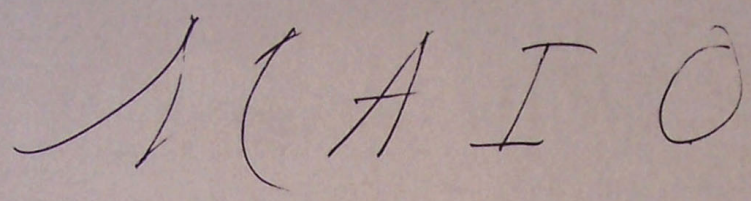

Juternational Fretry Muguryine Litited by Alferto de Lacerde Jumber one 


\section{3 \\ Pow Poesia 203 \\ MAIO}

International Poetry Magazine edited by Alberto de Lacerda

Number one

JORGE GUILLÉN

MURILO MENDES

OCTAVIO PAZ

ANNE BERESFORD

1

MÁRIO CESARINY

JÚLIO POMAR

DOMINIQUE FOURCADE

CELIA GILBERT

BEN NORWOOD

RUTH LEPSON

CLAUDE ROYET-JOURNOUD

AUGUSTO DE CAMPOS

DAVID WEVILL

LUÍS AMORIM DE SOUSA

DAVID STEILING

Covers by Jorge Guillén

1973 